\title{
A INSERÇÃO E AS CONTRIBUIÇÕES DOS INSTITUTOS FEDERAIS À FORMAÇÃO DE PROFESSORES
}

\author{
Gustavo Lopes Ferreira ${ }^{1}$ \\ Maria Luiza de Araújo Gastal²
}

\begin{abstract}
RESUMO:
Neste artigo discutimos a inserção dos Institutos Federais no cenário da formação de professores, considerando-os instituições recentes a oferecer esse tipo de formação. Quais seriam os motivos da atribuição aos IFs da função de formar professores? Com que prerrogativas legais realizam esse trabalho? Em quais regiões do Brasil predominam seus cursos de Licenciatura? Que contribuições esses espaços têm dado ou podem dar à formação de professores? Utilizamos como fonte documental pesquisas sobre o tema dos Institutos Federais e da formação de professores, a Lei no 11.892/2008 e dados da Plataforma Nilo Peçanha. As Licenciaturas nos IFs supririam parte da carência de professores no país, contribuiriam para a universalização do Ensino Médio e poderiam resolver o problema da atuação de tecnólogos e/ou bacharéis na docência. Até o ano de 2019, há 653 campi de IFs oferecendo 26 Licenciaturas, sendo 62,5\% da área de ciências e matemática, 25,5\% de ciências humanas e sociais e $12 \%$ de formação de professores para EPT. As contribuições dos institutos à formação de professores levam em conta a qualidade da Educação Básica de nível médio e da EPT e ainda o fato de que os IFs podem ampliar a formação docente para as áreas da EPT que tanto sofrem por falta de professores especializados.
\end{abstract}

Palavras-chave: formação docente; educação profissional; Instituto Federal de Educação, Ciência e Tecnologia.

\section{THE INSERTION AND CONTRIBUTIONS OF THE FEDERAL INSTITUTIONS TO TEACHER TRAINING}

\section{ABSTRACT}

In this paper we discuss the insertion of the Federal Institutes into the scenario of teacher training by considering them as recent institutions to offer that type of training. Why do the Federal Institutes have the function to train teachers? Which legal prerogatives do the Federal Institutes perform that work with? In which regions of Brazil do the teacher training courses predominate? Which contributions have that institutions been giving or may give to teacher training? We used as documental sources: a few researches about teacher training on the Federal Institutes, the Law no 11.892/2008 as well as some data from Nilo Peçanha Platform. The teacher training courses at the institutes would supply part of the lack of teachers in the country; they would contribute to the high school universalization and they could solve the problem of the action of technologists and/or bachelors at teaching. Since the year of 2019, there have been 653 campuses offering 26 teacher training courses from which $62,5 \%$ are related to the mathematics and science area, $25,5 \%$ human/social sciences and $12 \%$ teacher training for VTE. The contributions of the Federal Institutes to teacher training consider the quality of Basic Education of the high school and VTE as well as the fact that the institutes may expand the teacher training to VTE areas which struggle a lot with the lack of specialized teachers.

Keywords: teacher training; professional education; Federal Institution of Education, Science and Technology.

Recebido em: 22/6/2020

Aceito em: $15 / 11 / 2020$

\footnotetext{
1 Autor correspondente. Instituto Federal de Educação, Ciência e Tecnologia Goiano - Campus Ceres. Rodovia Go-154, Km 03, s/n. Ceres/ GO, Brasil. CEP 76300-000. http://lattes.cnpq.br/8216024102818214. http://orcid.org/0000-0002-4385-2962. gustavolofer@gmail.com

2 Universidade de Brasília - UNB. Brasília/DF, Brasil. http://lattes.cnpq.br/2848198350526854. http://orcid.org/0000-0002-1686-8475.
} 


\section{INTRODUÇÃO}

Neste artigo apresentamos resultados de parte de uma pesquisa de Doutorado cujo tema é a formação de professores de Ciências e Biologia nos Institutos Federais de Educação, Ciência e Tecnologia (IFs). Um de nossos objetivos foi o de compreender a entrada dos IFs no cenário da formação de professores, considerando-os instituições recentes a oferecer esse tipo de formação.

Em sua configuração contemporânea, os IFs possuem aproximadamente 14 anos de existência, refletindo na pouca produção acadêmica que trata da formação docente no âmbito dessas instituições. Para Ciavatta (2010, p. 163), "o tema dos institutos federais, na sua forma atual, é muito recente para resultados de pesquisa". Nossa proposta buscou suprir parte dessa lacuna, questionando: Quais seriam os motivos da atribuição aos IFs da função de formar professores? Com que prerrogativas legais realizam esse trabalho? Em quais regiões do Brasil predominam seus cursos de formação de professores? Quais cursos/áreas são privilegiados/as? E urgentemente: Que contribuições os IFs têm dado ou podem dar ou tem dado à formação de professores?

Para traçar respostas a esses questionamentos, utilizamos como fonte documental algumas pesquisas divulgadas sobre os IFs e a formação de professores nestes locais (MAGALHÃES; CASTIONI, 2019; SILVA; MELO, 2018; GEBRIM, 2017; CAMARGO; CASTRO, 2016; PANIAGO, 2016; FLACH, 2014; LIMA, 2012; CIAVATTA, 2010; CAMPELLO, 2007); a Lei no 11.892, de 29 de dezembro de 2008, que instituiu a Rede Federal de Educação Profissional, Científica e Tecnológica (RFEPCT) e criou os IFs; e a Plataforma Nilo Peçanha (PNP), que publica dados oficiais e atualizados sobre a RFEPCT.

A PNP disponibiliza informações atualizadas sobre diferentes aspectos da RFEPCT, detalhando dados ao nível de cada unidade de ensino, sendo alimentada pelo Sistema Integrado de Administração de Recursos Humanos (Siape), Sistema Integrado de Administração Financeira (Siafi) do governo federal e pelo Sistema Nacional de Informações da Educação Profissional e Tecnológica (Sistec) da Secretaria de Educação Profissional e Tecnológica do Ministério da Educação (Setec/MEC). A PNP entrou no ar no ano de 2018, constituída como um ambiente virtual de coleta, validação e divulgação das estatísticas oficiais da RFEPCT (BRASIL, 2019b).

Em consulta e análise a essas fontes de informação, constatamos que os IFs estão inseridos em uma série de políticas públicas e de reformas educacionais instituídas ao longo de anos. Embora tenham aspecto de novidade, segundo Silva e Melo (2018), os institutos surgem em um contexto de reestruturação de antigas instituições já consolidadas. Diante disso, neste texto retomamos alguns marcos que repercutiram na atual configuração dos IFs, entendendo que, recentemente, essas instituições receberam a incumbência de atuar também na formação de professores, ao lado do seu histórico compromisso com a educação profissional e tecnológica (EPT).

Na primeira parte do texto traçamos a constituição histórica dos IFs destacando os motivos que levaram essas instituições a atuar na formação docente, o que culminou com a promulgação da lei que criou os institutos e deu embasamento legal para formarem professores. Na segunda parte evidenciamos os cursos de Licenciatura e sua distribuição pelos campi dos IFs, apresentando uma caracterização geral desses cursos. 
A partir disso, procuramos as contribuições que essas instituições têm dado ou podem dar à formação de professores. Na conclusão revelamos nossa preocupação com a formação de professores no Brasil, diante de ataques à Educação Pública, advento do contexto histórico-social iniciado no ano de 2016 com o golpe contra à presidente Dilma Rousseff, passando pela promulgação da Emenda Constitucional no 95, que congelou os gastos públicos por 20 anos, inclusive em Educação e Saúde, até a ascensão do governo de extrema-direita de Jair Bolsonaro.

\section{A CONSTITUIÇÃO HISTÓRICA DOS IFS}

O compromisso com a EPT faz parte da agenda dos IFs desde os primórdios, claro que assumindo facetas diferentes. Ainda no ano de 1909, o então presidente do Brasil, Nilo Peçanha, por meio do Decreto n. 7.566 (BRASIL, 1909), determinou a criação de 19 escolas de aprendizes e artífices, instituindo uma rede profissional de ensino (GEBRIM, 2017; PANIAGO, 2016; FLACH, 2014; LIMA, 2012).

O trabalho de Gebrim (2017) nos traz uma importante contribuição para o conhecimento dos IFs ao narrar um panorama da EPT no país, analisando leis e decretos sobre tal temática. Na leitura deste trabalho percebemos que o percurso da EPT e, por conseguinte, dos IFs, é marcado por políticas governamentais que foram redefinindo seus papéis. Resumidamente, as escolas de aprendizes e artífices passaram a ser denominadas, em 1937, de Liceus Industriais, para mudarem novamente em 1942, quando sofreram "nova alteração, transformando-se em Escolas Técnicas e Escolas Industriais, ambas, em sua soma, cobrindo todo o território nacional" (GEBRIM, 2017, p. 18).

As Escolas Industriais e Escolas Técnicas da União, por sua vez, foram elevadas ao nível de autarquias, garantindo autonomia didática, administrativa, técnica e financeira em 1959, durante governo de Juscelino Kubitschek (GEBRIM, 2017), originando, com isso, as Escolas Técnicas Federais - ETF (PANIAGO, 2016).

No governo militar de Ernesto Geisel, em 1979, três ETFs, de Minas Gerais, Paraná e Rio de Janeiro, foram transformadas em Centros Federais de Educação Tecnológica (Cefets) (GEBRIM, 2017; PANIAGO, 2016). Com objetivos diferenciados, essas instituições introduziram no cenário da educação técnica uma reorientação, passando a atuar também no Ensino Superior. Foram criados cursos técnicos integrados ao segundo grau, ao lado de cursos de Graduação e Pós-Graduação em Engenharia e Pós-Graduação (CAMPELLO, 2007). Complementando, Ciavatta (2010, p. 164) relata que os Cefets criados nos anos de 1970 passaram a ofertar "licenciatura plena e curta para formar professores e especialistas para disciplinas especializadas do Ensino Médio e a formação de tecnólogos".

Os Cefets, contudo, somente iniciaram sua consolidação no governo de Itamar Franco, com a Lei no 8.948/94, que instituiu o Sistema Nacional de Educação Tecnológica (CIAVATTA, 2010, p. 164). Assim, o movimento de transformação das ETF em Cefets concretizou-se, a partir de 1999, pelo Decreto no 2.406 de 1997 (CAMPELLO, 2007), o que resultou em que "entre 1997 e 2002 todas as ETF e demais dez Escolas Agrotécnicas Federais foram transformadas em CEFETs" (FLACH, 2014, p. 56). 
Campello (2007) relata que nos anos de 1990 houve uma nova reorientação dos Cefets, que passaram a ser centros especializados em educação profissional, ofertando cursos técnicos pós-médios e de formação de tecnólogos. Isto foi diferente do que aconteceu aos Cefets em 1970 (CIAVATTA, 2010), quando eles se caracterizaram mais como Instituições de Ensino Superior (IES).

Conforme Silva e Melo (2018, p. 6), "os CEFETs deram início a um modelo alternativo de ensino superior, passaram pelas Escolas Agrotécnicas Federais, tornaram-se proeminentes na Universidade Tecnológica Federal do Paraná (UTFPR) e, mais tarde, consolidaram-se nos IFs". A partir disso, evidenciamos que os Cefets estão na origem da oferta de Ensino Superior na educação profissional, pois àquelas instituições foi dada a incumbência de ministrar Ensino Médio, Graduação e Pós-Graduação Tecnológica e Licenciatura para o Ensino Médio (GEBRIM, 2017).

CConcordamos com Camargo e Castro (2016) em que a implantação de um modelo alternativo de educação superior acabou por introduzir também os IFs como um novo lócus de formação docente, alavancado pelos antigos Cefets. Ainda, estas autoras, pautadas em Silva e Castro (2007), mostram que a implicação dos IFs com a formação de professores tem levado a uma formação técnica e instrumental já arraigada nos Cefets, não priorizando uma sólida formação teórico-prática. Em contraposição, para Caldas (2011) os IFs consolidam uma experiência bem-sucedida, ainda recente, dos Cefets na oferta de Licenciatura para disciplinas da área científica da Educação Básica.

É importante destacarmos que durante esse movimento que originou os Cefets a formação docente aguardava o estabelecimento das primeiras diretrizes curriculares das Licenciaturas, que só foram publicadas em 2002, mas que já eram exigidas desde o ano de 1996 na Lei de Diretrizes e Bases da Educação Nacional (LDB), no 9.394, de 20 de dezembro de 1996. A promulgação dessa lei, no artigo 62, estabeleceu que:

A formação de docentes para atuar na Educação Básica far-se-á em nível superior, em curso de licenciatura plena, admitida, como formação mínima para o exercício do magistério na educação infantil e nos cinco primeiros anos do ensino fundamental, a oferecida em nível médio, na modalidade normal (BRASIL, 1996).

A urgência em formar professores em nível superior e a necessidade de explicitar como seria essa formação exigiu esforços de várias frentes, incluindo os Cefets. Em maio do ano 2000 o então presidente da República, Fernando Henrique Cardoso, estendeu aos Cefets a autonomia para a "criação e implantação de cursos de formação de professores para as disciplinas científicas e tecnológicas do Ensino Médio e da Educação Profissional" (BRASIL, 2000, p. 1). Essas instituições passaram a ter o aval legal para ministrar Licenciaturas, com o objetivo explícito de suprir carências de professores habilitados no país (FLACH, 2014) e atender ao disposto da LDB no 9.394/1996. Esse discurso voltaria à cena recentemente quando da criação dos IFs.

Ao retornarmos à literatura voltada ao assunto dos Cefets, algumas publicações revelam que houve problemas na criação dos programas de formação docente devido, principalmente, à falta de tradição e de condições estruturais para tal oferta. Reforçamos que desde sua origem os Cefets cumpriram e ainda cumprem um importante papel 
no cenário da EPT, e, por tal compromisso, muitos autores acenam para a impossibilidade de ampliação de suas funções de modo a incluir a formação de professores da Educação Básica (FLACH, 2014; LIMA, 2012).

No ano de 2004, sob a presidência de Luís Inácio Lula da Silva, foram retomadas as discussões acerca das políticas federais para a EPT e ampliação do acesso ao Ensino Superior. Silva e Melo (2018) constataram que no período de 2003 a 2013 houve aumento do número de matrículas na educação superior pública em contraste com o período de 1995 a 2003.

Ainda na gestão do governo Lula também foram publicadas, em 2006, as novas Diretrizes Curriculares Nacionais para a Formação de Professores da Educação Básica (DCN), fomentando ações para que todos os professores tivessem formação superior. Esse é um dos motivos da atribuição aos IFs da função de formar professores. Essas instituições sintonizaram-se, então, com essas diretrizes de 2006 e não se voltaram à formação docente de nível médio, mas, sim, a de nível superior, o que também deu força ao movimento de valorização da profissão.

Os trabalhos de Maués, Segenreich e Otranto (2015) e Lima (2012) apontam as medidas adotadas com vistas a expandir o Ensino Superior por meio dos cursos de formação de professores. Ambos os trabalhos criticam a política do governo de Fernando Henrique Cardoso por promover um sucateamento do ensino público superior e a privatização da formação neste nível de ensino. Em contrapartida, os governos Lula (2003-2010) e Dilma (2011-2016) são percebidos como aqueles em que houve o aumento expressivo dos gastos com o sistema federal de ensino, o que, dentre outras coisas, contribuiu para a criação dos IFs. Segundo Magalhães e Castioni (2019, p. 741 apud BREZINSKI et al., 2017), [...] "o orçamento da Rede Federal de EPT, que passou de 6,81\% do total do MEC, em 2005, para 10,49\%, em 2015".

Na esteira das medidas de fortalecimento e ampliação da EPT e do Ensino Superior na RFEPCT "foram desencadeadas ações de reordenamento das IES públicas, com princípios de otimização de espaços e tempos, de ampliação e criação de oferta, de redução ou flexibilização de recursos materiais e humanos" (SILVA; MELO, 2018, p. 5). Por esse motivo decidiu-se pelo aproveitamento da estrutura dos Cefets transformando algumas unidades em IFs, a fim de que as condições previamente instaladas pudessem auxiliar na formação de professores também. Foi assim que, no ano de 2007, começou a delinear-se o desenho que culminou na criação da RFEPCT.

Como desdobramento disso, após consulta pública e negociação da Setec/MEC junto as instituições que se submeteriam ao reordenamento da EPT, "nos últimos dias do ano de 2008, a Lei № 11.892, de 29 de dezembro, instituiu a Rede Federal de Educação Profissional, Científica e Tecnológica (RFEPCT)" (GEBRIM, 2017, p. 47). Foram criados os 38 Institutos Federais espalhados por quase todo território nacional.

Segundo Pacheco (2012) e Paniago (2016), os IFs foram criados a partir do potencial instalado nos 31 CEFETS, nas 75 unidades descentralizadas de ensino (Uned), nas 39 Escolas Agrotécnicas, nas 7 escolas técnicas federais e nas 8 escolas vinculadas às universidades federais. Todas essas instituições, por força da Lei e por adesão volun- 
tária, se transformaram em IFs. Ressaltamos que a RFEPCT é constituída ainda pela UTFPR, pelos Cefets RJ e MG, Escolas Técnicas Vinculadas às universidades federais e pelo Colégio Pedro II (BRASIL, 2008, artigo 1ㅇ).

Os IFs são definidos, no 2 을 artigo da Lei no 11.892/2008, "como instituições de educação superior, básica e profissional, pluricurriculares e multicampi, especializados na oferta de educação profissional e tecnológica nas diferentes modalidades de ensino". O que destacamos desse artigo é que os institutos trazem, em sua gênese, o compromisso com a verticalização do ensino, oferecendo a oportunidade para que seus estudantes possam cumprir diferentes níveis e modalidades, da educação básica à educação profissional e educação superior.

A verticalização é vista por Lima (2012) como um fator diferencial dos IFs em relação a outras instituições, inclusive as da própria RFEPCT. Por isso, os institutos ainda mantêm vínculos com suas raízes na EPT, o que é respaldado na Lei de sua criação, que define que, no mínimo, $50 \%$ das vagas sejam para a educação profissional técnica de nível médio (BRASIL, 2008, artigo 8ㅇ).

Por outro lado, com o advento da RFEPCT, os IFs se consolidaram como mais um lócus de formação de professores (CAMARGO; CASTRO, 2016). Os institutos encontram respaldo na prerrogativa da Lei para ofertar uma parcela de, no mínimo, $20 \%$ de vagas em cursos voltados à formação de professores, seja Licenciatura, seja em programas especiais de formação pedagógica ou Pós-Graduações (BRASIL, 2008, artigo 8ㅇ).

No âmbito da educação superior, os IFs podem ofertar cursos superiores de tecnologia, bacharelados e engenharias. Sacramentando a verticalização, ainda podem oferecer Especializações, Mestrados e Doutorados. Dado seu status de instituição universitária, as atividades de ensino, pesquisa e extensão também estão implicadas na constituição dos IFs. Diante dessa multiplicidade de atuação, como lidar com professores polivalentes, muitas vezes sem formação específica tanto para atuar com as disciplinas direcionadas à EPT quanto em outros níveis e modalidades de ensino como as Licenciaturas?

Outra face que merece ser demarcada é a estreita relação dos IFs com as demandas sociais locais, prevista inclusive no artigo 60 da própria Lei, que trata das finalidades e características do IFs. No inciso IV está posto que os institutos devem "orientar sua oferta formativa em benefício da consolidação e fortalecimento dos arranjos produtivos, sociais e culturais locais, identificados com base no mapeamento das potencialidades" (BRASIL, 2008). Silva e Melo (2018) explicam que tal objetivo faz parte da política educacional adotada pelo governo após o ano de 2003, a qual submeteu a educação a necessidades e demandas dos arranjos produtivos locais (APL). Ainda para essas autoras, nos IFs isso acontece desde a Educação Básica nos cursos técnicos integrados ao Ensino Médio até o Ensino Superior. Mota (2015) e Castioni (2012) enxergam no compromisso com o desenvolvimento local uma marca justificadora para os IFs.

A promoção da interiorização do ensino pelos IFs é um dos aspectos mais vantajosos quando pensamos em sua atuação. Incrementar os IFs como possibilidade de formação de professores se faz importante como tentativa de ampliar o número de docentes da Educação Básica formados em nível superior, especialmente em localidades onde mais faltam professores graduados, o interior do país. Além disso, amplamente 
os institutos permitem que uma parcela da população, localizada em regiões economicamente desfavorecidas e de cidades pequenas, possa ter acesso à educação pública, gratuita e de qualidade.

O caráter público do trabalho formativo dos IFs contrapõe-se à formação de professores em instituições privadas de Ensino Superior que ainda predominam na formação de professores no Brasil. No trabalho de Neves (2012) são identificadas duas ondas de expansão do Ensino Superior brasileiro ${ }^{3}$ que privilegiaram instituições privadas de ensino:

[...] até início dos anos 80, o crescimento da matrícula no ensino superior deu-se de modo acelerado, podendo se identificar uma primeira onda de expansão. 0 crescimento foi retomado no final da década de 1990 quando ocorre uma segunda onda de expansão (p. 6).

A LDB/96 contrapôs-se à baixa quantidade de professores da Educação Básica com formação apenas em nível médio e passou a impulsionar políticas de formação de professores direcionadas à qualificação docente em nível superior. Com isso, Camargo e Castro (2016) afirmam que houve o fortalecimento de instituições privadas no Ensino Superior para atender à demanda por formação.

Atualmente, embora as IES privadas ainda detenham o maior quantitativo de matrículas na Educação Superior, Silva e Melo (2018) ressaltam que houve um crescimento significativo no número de matrículas neste nível de ensino na rede pública no período de 2003 a 2013, sendo 83\% maior do que o registrado no período de 1995 a 2003 . No caso das Licenciaturas, cursos direcionados à formação inicial de professores, segundo dados do Censo da Educação Superior de 2018, aproximadamente 62,4\% das matrículas do país estão em IES privadas, enquanto $37,6 \%$ estão matriculados na rede pública (BRASIL, 2019a).

\section{A INSERÇÃO E AS CONTRIBUIÇÕES DOS IFS À FORMAÇÃO DE PROFESSORES}

A expansão do Ensino Superior no Brasil intensificou-se desde a década de 90 do século 20 e veio acompanhada de alguns elementos, como novas formas de organização institucional e novas modalidades de ensino e de cursos (SEGENREICH; CASTANHEIRA, 2009). Isso fica claro quando se analisa a criação dos IFs. Assim, observamos que a formação de professores nos IFs constitui, juntamente com outros elementos, uma das medidas que vai ao encontro dessa expansão do Ensino Superior brasileiro.

O que motivou a criação de Licenciaturas nos IFs? Para Paniago (2016), os IFs seriam uma saída para buscar resolver o problema da falta de professores com formação para atuar na Educação Básica. Já Silva e Melo (2018, p. 7), pautadas no documento “Uma nova proposta de Educação Profissional Tecnológica: concepções e diretrizes dos

\footnotetext{
Na década de 80 do século 20, sob regime militar, o Ensino Superior privado e pago não contava com subsídios governamentais e reafirmava o caráter elitista do ensino público, pois somente a elite poderia dar continuidade aos seus estudos (NEVES, 2012). No final da década de 90, também do século 20, demandou-se o aumento do nível de escolarização da população e consequente crescimento da matrícula no Ensino Médio, pressionando para que se tivesse início a segunda onda de expansão do Ensino Superior no Brasil. "Uma diferença fundamental, nesse momento, é a crescente demanda das classes de menor poder aquisitivo pelo acesso ao ensino superior" (NEVES, 2012, p. 6).
} 
Institutos Federais" (BRASIL, 2010), fundamentam o argumento de que as Licenciaturas nos IFs, além de suprirem a carência de professores, viabilizariam o cumprimento da meta de universalização do Ensino Médio e poderiam resolver "o problema da predominância da atuação de técnicos e bacharéis nos mais variados campos e, na última década, maciçamente, a presença dos tecnólogos e/ou bacharéis na função docente".

Outra motivação para a oferta de formação de professores nos IFs foi a pressão causada pela publicação do primeiro Plano Nacional de Educação (PNE), em 2001, que exigia ações rápidas para solucionar o problema da falta de professores formados em atuação (BRASIL, 2001).

O trabalho de Lima (2012) sinaliza dois problemas que decorrem da inserção da formação de professores nos IFs: o aumento no número de cursos e vagas, por si só, não garante que os docentes formados irão atuar nas escolas básicas; e a falta de vocação histórica dos IFs na oferta de formação docente. Quanto ao primeiro problema, percebemos que a questão é de como motivar as pessoas para a profissão professor diante da "baixa atratividade da carreira, da precariedade nas condições de trabalho, o que dificulta a valorização do trabalhador docente e, em consequência, reduz a procura pelas licenciaturas e pela profissão" (CAMARGO; CASTRO, 2016, p. 123). Quanto ao segundo problema, o enxergamos com um olhar otimista, considerando que a diversificação e integração entre os diferentes níveis e modalidades de ensino, do básico ao superior, é um diferencial que pode contribuir para a qualidade da formação de professores no âmbito dos IFs.

A política que embasa os IFs e a RFEPCT vai no sentido de expandir a EPT e a formação de professores. No portal eletrônico do MEC encontramos alguns dados interessantes que apoiam a proposta da RFEPCT no que diz respeito à construção de novas unidades espalhadas pelos Estados brasileiros (Figura 1).

Figura 1 - Expansão da RFEPCT mostrando o número de unidades construídas entre os anos de 1909 e 2016

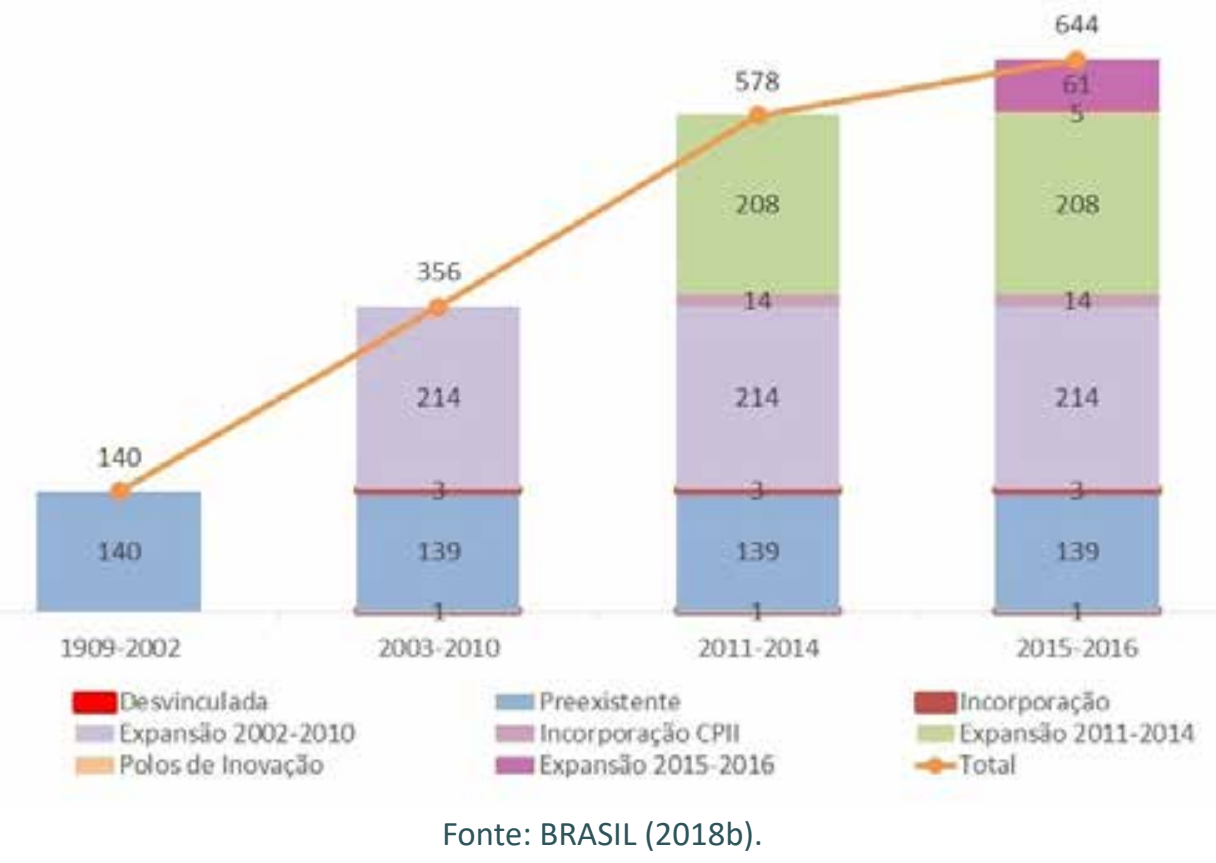


Apresentamos a Figura 1 para destacar o quantitativo de unidades que foram construídas ao logo de cem de anos de história da EPT. Entre 1909 e 2002 foram criadas 140 escolas técnicas no país. De 2003 a 2016 já se somam 500 novas unidades referentes ao plano de expansão da educação profissional, o que totaliza 644 campi em funcionamento (BRASIL, 2018). Na última consulta à PNP verificamos que, no ano de 2019, a RFEPCT estava constituída por 653 unidades. O crescimento expressivo da RFEPCT salta aos olhos, atestando sua robustez e a capilaridade do modelo de educação a ela vinculado, presente em todo território brasileiro. Novamente a interiorização aparece em destaque.

Lançando foco sobre a formação de professores, obtivemos, na PNP, alguns dados atualizados do ano de 2019 a respeito das Licenciaturas. Dialogamos diretamente com a pesquisa de Lima, que produziu, no ano de 2012, um panorama sobre os cursos de formação de professores nos IFs. Percebemos que, daquele tempo para este, muita coisa mudou.

A pesquisa de Lima (2012) reforçou que, em decorrência da existência dos IFs em 2008 , houve um aumento significativo no número de cursos de Licenciatura oferecidos por tais instituições. Antes da Lei no 11.892/2008 eram 103 cursos, segundo dados recolhidos pela autora no Sistema e-MEC. Após a Lei e até os dias atuais, conforme o PNP (BRASIL, 2019b), já se somam 795, um aumento de $87 \%$. Esse crescimento substancial das licenciaturas é resultado da própria política de governo que deu origem aos IFs, colocando-os como um novo lócus de formação de professores.

A distribuição dos cursos de Licenciatura ofertados pelos IFs está em consonância com a Lei no 11.892 e com uma das concepções que a subjaz: o desenvolvimento regional. Esse aspecto está apoiado no discurso de interiorização, cuja marca se faz presente nos IFs. Segundo Magalhães e Castioni (2019, p. 740-741), "acreditava-se que a oferta EPT era importante para gerar novas oportunidades de trabalho em outras regiões do país, uma vez que a oferta EPT estava muito concentrada na faixa litorânea e em poucas cidades grandes".

Os IFs, ao garantirem a existência de unidades em cidades menores e interioranas, não impactaram necessariamente sobre a EPT. Nesse sentido, Magalhães e Castioni (2019) demonstraram que a expansão para os interiores do Brasil não teve força suficiente para alterar significativamente o quadro da EPT, pois os IFs parecem reforçar a tradição bacharelesca que domina o imaginário nacional, ou seja, valorizam o Ensino Superior e não a formação técnica.

Reconhecemos que permitir o acesso à educação EPT e ao Ensino Superior em regiões economicamente desfavorecidas é uma iniciativa importante da política de criação dos IFs. Esse é o caso da Região Nordeste, que detém o maior número de IFs - um total de 209, apresentando também o maior quantitativo de cursos de Licenciatura, 314 (BRASIL, 2019b). Os dados são expressivos e ilustram o que tem sido a política instituída pelos IFs, com vistas a levar educação a regiões que, historicamente, possuem déficit de professores com formação em nível superior. Segundo Gatti e Barreto (2009), 48\% dos docentes do Nordeste não possuem tal formação. 
A Tabela 1 foi elaborada após consulta à PNP. Por meio dela, apresentamos a distribuição de cursos de Licenciatura nos IFs pelas nas cinco regiões brasileiras no ano de 2019, comparando com dados do ano de 2012 da pesquisa de Lima (2012). Ressaltamos que a categoria "unidades" refere-se às unidades de ensino, ou ao campus que tem matrículas vinculadas na modalidade Licenciatura.

Tabela 1 - Quantitativo de campi que ofertam Licenciatura, de cursos de Licenciatura e de matrículas nos cursos de Licenciatura nos IFs distribuídas por região

\begin{tabular}{ccccccccccc}
\hline Região & \multicolumn{4}{c}{ Unidades } & \multicolumn{3}{c}{ No de Licenciaturas } & \multicolumn{2}{c}{$\begin{array}{c}\text { No de } \\
\text { matrículas }\end{array}$} \\
\hline & Em 2012 & Em 2019 & \multicolumn{3}{c}{ Em 2012 } & Em 2019 & Em 2019 \\
Nordeste & 11 & $29 \%$ & 122 & $35,6 \%$ & 127 & $38,5 \%$ & 314 & $39,5 \%$ & 36.791 & $38,6 \%$ \\
Sudeste & 9 & $24 \%$ & 73 & $21,3 \%$ & 75 & $23 \%$ & 164 & $20,6 \%$ & 24.694 & $25,9 \%$ \\
Sul & 6 & $16 \%$ & 61 & $17,8 \%$ & 52 & $16 \%$ & 119 & $15,0 \%$ & 11.735 & $12,3 \%$ \\
Centro-Oeste & 5 & $13 \%$ & 46 & $13,4 \%$ & 28 & $8,5 \%$ & 81 & $10,2 \%$ & 11.786 & $12,3 \%$ \\
Norte & 7 & $16 \%$ & 41 & $11,9 \%$ & 47 & $14 \%$ & 117 & $14,7 \%$ & 10.379 & $10,9 \%$ \\
Total & $\mathbf{3 8}$ & $\mathbf{1 0 0 \%}$ & $\mathbf{3 4 3}$ & $\mathbf{1 0 0 \%}$ & $\mathbf{3 2 9}$ & $\mathbf{1 0 0 \%}$ & $\mathbf{7 9 5}$ & $\mathbf{1 0 0 \%}$ & $\mathbf{9 5 . 3 8 5}$ & $\mathbf{1 0 0 \%}$ \\
\hline
\end{tabular}

Fonte: Elaborada pelos autores a partir de dados da PNP (BRASIL, 2019b) e de LIMA (2012).

Evidenciamos que houve uma expansão significativa na oferta de Licenciaturas em todas as regiões, correspondendo a um aumento de: Nordeste - 147,2\%; Sudeste -118,7\%; Sul - 128,8\%; Centro-oeste - 189,3\%; Norte - 148,9\%. Em média, as Licenciaturas cresceram $146,6 \%$ em todas as regiões nos últimos oito anos.

A expansão da RFEPCT entre os anos de 1909 e 2019, ano da última coleta de dados da PNP, representou uma diferença de 513 unidades construídas. Essa ampliação veio acompanhada, também, do aumento dos cursos de formação de professores no âmbito dos IFs, em decorrência da aplicação da Lei no 11.892/2008. Consideramos que essa crescente oferta de Licenciaturas tem gerado a necessidade de ampliação de condições para atender às demandas da formação de professores para além das condições preexistentes nos antigos Cefets e demais instituições que se transformaram em IFs após 2008. A expansão de cursos veio acompanhada pelo aumento do orçamento investido na RFEPCT, cujas despesas totais tiveram contínuo crescimento no período 2005-2017 de 462\% (BRASIL, 2018).

Atualmente, nos IFs, há 26 cursos/áreas destinados à formação de professores em nível superior, conforme Tabela 2, inspirada no trabalho de Lima (2012).

Tabela 2 - Relação em ordem decrescente de quantidade de cursos de Licenciatura oferecidos e sua oferta pelas unidades dos IFs

\begin{tabular}{|c|c|c|c|c|c|}
\hline \multirow[b]{2}{*}{1} & \multirow{2}{*}{$\begin{array}{c}\text { Cursos } \\
\text { Matemática }\end{array}$} & \multicolumn{2}{|c|}{$\begin{array}{c}\text { Quantidade de unidades } \\
\text { que oferecem }\end{array}$} & \multicolumn{2}{|c|}{$\begin{array}{l}\text { Quantidade de } \\
\text { cursos oferecidos }\end{array}$} \\
\hline & & 103 & $30,0 \%$ & 136 & $17,1 \%$ \\
\hline 2 & Química & 92 & $26,8 \%$ & 120 & $15,1 \%$ \\
\hline 3 & Ciências Biológicas & 82 & $23,9 \%$ & 116 & $14,6 \%$ \\
\hline 4 & Física & 75 & $21,9 \%$ & 107 & $13,4 \%$ \\
\hline 5 & Pedagogia & 54 & $15,7 \%$ & 62 & $7,8 \%$ \\
\hline 6 & Letras - Língua Portuguesa & 27 & $7,9 \%$ & 35 & $4,4 \%$ \\
\hline \multicolumn{6}{|c|}{$\begin{array}{l}\text { Contexto \& Educação } \\
\text { Editora Unijui • ISSN 2179-1309 • Ano } 36 \bullet \text { no } 115 \bullet \text { Set./Dez. } 2021\end{array}$} \\
\hline
\end{tabular}




\begin{tabular}{|c|c|c|c|c|c|}
\hline 7 & $\begin{array}{l}\text { Licenciatura para Educação } \\
\text { Profissional, Científica e Tecnológica }\end{array}$ & 22 & $6,4 \%$ & 26 & $3,3 \%$ \\
\hline 8 & Geografia & 17 & $4,9 \%$ & 26 & $3,3 \%$ \\
\hline 9 & Computação & 19 & $5,5 \%$ & 23 & $2,9 \%$ \\
\hline 10 & $\begin{array}{l}\text { Programa Especial de Formação } \\
\text { Pedagógica de Docentes }\end{array}$ & 20 & $5,8 \%$ & 20 & $2,5 \%$ \\
\hline 11 & Ciências da Natureza & 12 & $3,5 \%$ & 18 & $2,3 \%$ \\
\hline 12 & Educação Física & 12 & $2,0 \%$ & 16 & $2,0 \%$ \\
\hline 13 & Informática & 9 & $2,6 \%$ & 14 & $1,8 \%$ \\
\hline 14 & Letras - Língua Estrangeira & 7 & $2,0 \%$ & 13 & $1,9 \%$ \\
\hline 15 & Letras & 9 & $2,6 \%$ & 11 & $1,4 \%$ \\
\hline 16 & Ciências Agrárias & 7 & $2,0 \%$ & 11 & $1,4 \%$ \\
\hline 17 & Música & 7 & $2,0 \%$ & 11 & $1,4 \%$ \\
\hline 18 & Educação do Campo & 7 & $2,0 \%$ & 7 & $0,9 \%$ \\
\hline 19 & Ciências Sociais & 4 & $1,2 \%$ & 5 & $0,6 \%$ \\
\hline 20 & Artes Visuais & 4 & $1,2 \%$ & 4 & $0,5 \%$ \\
\hline 21 & Teatro & 3 & $0,9 \%$ & 4 & $0,5 \%$ \\
\hline 22 & História & 3 & $0,9 \%$ & 3 & $0,4 \%$ \\
\hline 23 & Dança & 2 & $0,6 \%$ & 3 & $0,4 \%$ \\
\hline 24 & Libras - Licenciatura & 2 & $0,6 \%$ & 2 & $0,2 \%$ \\
\hline 25 & Artes Cênicas & 1 & $0,3 \%$ & 1 & $0,1 \%$ \\
\hline 26 & Intercultural Indígena & 1 & $0,3 \%$ & 1 & $0,1 \%$ \\
\hline
\end{tabular}

Fonte: Elaborada pelos autores a partir de dados da PNP (BRASIL, 2019b).

Os cursos de Matemática e as Licenciaturas em Química, Ciências Biológicas e Física são os mais ofertados pelos IFs. Entendemos que isso se deve à Lei de criação dessas instituições que, por sua vez, segue o que está disposto no Plano Nacional de Educação (PNE) do ano de 2001. Tanto na lei quanto no PNE as áreas de ciências e matemática são prioritárias. Se somarmos a quantidade daquelas Licenciaturas com a de Ciências da Natureza, juntas compõem 62,5\% da oferta dos IFs. Lima (2012) já observava uma forte tendência dos IFs por cursos das áreas de ciências e matemática, com percentual de $72 \%$.

Na Lei que deu origem aos IFs, a formação de professores para a EPT é contemplada. Notamos, no entanto, que os cursos que atendem ou poderiam atender a esta demanda, como Ciências Agrárias, Computação, Informática, Licenciatura para Educação Profissional, Científica e Tecnológica e Programa Especial de Formação Pedagógica de Docentes, possuem pouca expressividade, correspondendo a $12 \%$ da oferta. Os dois últimos cursos são direcionados a bacharéis e tecnólogos que desejam obter o grau de Licenciatura, reforçando a necessidade de formar professores para disciplinas específicas da área EPT. Lima (2012) também encontrou escassez desse tipo de formação, que representou apenas $12 \%$ dos cursos de formação de professores dos IFs.

Diante da inexpressiva quantidade de cursos voltados à formação para a EPT, refletimos: Onde, quem e como são formados os docentes que atuam nas disciplinas da área profissional e tecnológica? Observamos no cenário nacional a quase inexistência deste tipo de formação (MACHADO, 2008), até mesmo nos IFs, instituições que carregam a EPT em seu nome e em sua prática. Parece-nos que a formação para tais áreas 
seria uma prioridade e uma marca distintiva para os institutos. Atuar na formação de professores para a EPT talvez seja uma das contribuições mais relevantes que os IFs podem dar à formação de professores do país.

Ainda dialogando sobre o perfil das Licenciaturas dos IFs, notamos que os cursos das áreas de ciências sociais e humanas ${ }^{4}$ representam mais do que o dobro da quantidade daqueles voltados à EPT, totalizando $25,5 \%$ das Licenciaturas dos IFs. Embora os IFs sejam vocacionados à EPT, Magalhães e Castioni (2019) tecem críticas que essas instituições:

[...] têm se tornado mais um espaço de produção de ativos intelectuais na direção para a manutenção das mesmas estruturas sociais, isto é, uma "EPT" apenas para futuras atividades especializadas e para o acesso ao ensino superior nas universidades públicas (p. 747).

Parece que a multiplicidade de cursos de Licenciatura mostra que os IFs vieram para contribuir com a formação docente do país, assumindo o compromisso de formar professores a fim de atender à demanda pela profissionalização. No ano de 2019 os IFs tinham 95.385 matriculados nas Licenciaturas e 27.595 vagas criadas nas Licenciaturas (BRASIL, 2019b). Antes deste período, Camargo e Castro (2016) já observavam a ampliação de matrículas nas licenciaturas do país entre os anos de 2009 e 2010, o que tem relação direta com a política de criação de novas instituições federais de Ensino Superior, ocorrida a partir do governo de Luiz Inácio Lula da Silva (2003-2010). Esses números não podem ser desconsiderados. Enxergamos tal quantitativo como um sinal de esperança de que a ampliação de espaços formativos permitirá alcançar melhorias no cenário de formação docente brasileiro, claramente a partir de um trabalho sério, comprometido e engajado com as árduas lutas pela valorização da profissão: melhores salários, planos de carreira, condições estruturais das escolas e dos cursos de formação e participação dos professores no delineamento de políticas públicas de educação.

Ao ampliar o lócus de formação de professores, os IFs tornaram-se uma opção a mais de itinerário formativo ao lado de outras instituições, como universidades, faculdades e centros universitários. Para Camargo e Castro (2016, p. 141), "isso vem corroborar o entendimento de que a centralidade da formação de professores é dividida com outras IES, o que contribui para a diversidade da formação de professores, já que elas apresentam diferentes missões institucionais".

Por outro lado, Silva e Melo (2018) expõem que a ampliação, expansão e flexibilização da formação de professores fizeram proliferar no Brasil, além de instituições diversificadas, cursos flexíveis, com o objetivo de reduzir gastos públicos, promover abertura comercial e privatizações por meio de políticas educacionais. Próximo a essa ideia, Camargo e Castro (2016, p. 131) afirmam que os IFs "priorizam aspectos de natureza quantitativa, valorizam a otimização dos recursos e a instrumentalização da formação, mesmo que sob o discurso da qualidade do processo educacional".

Os seguintes cursos compõem a área de ciências sociais e humanas: Artes Cênicas, Artes Visuais, Ciências Sociais, Dança, Educação do Campo, Educação Física, Geografia, História, Intercultural Indígena, Letras, Letras - Língua Estrangeira, Letras - Língua Portuguesa, Libras, Música, Pedagogia, Teatro. 
A fundação de outras IES, para além dos espaços universitários, com a formação de professores, aprofundou o processo de fragmentação e uma abordagem tecnicista, trazendo para o cenário instituições tradicionalmente ligadas à EPT, além de não permitir a criação e manutenção de uma base comum de formação docente (FREITAS, 1999; CAMPELLO, 2007; LIMA, 2012). Os IFs possuem uma longa tradição com a EPT, no entanto a formação de professores é ainda novidade, e é nesta direção que são realizadas críticas.

Freitas (1999) afirma que a fragmentação da formação docente vai contra a luta da Associação Nacional pela Formação dos Profissionais da Educação (Anfope) por uma base comum nacional para formar professores. Gatti e Barreto (2009) indagam-se a respeito da contribuição que as IESs com escassa ou nenhuma tradição acadêmica na formação para o magistério podem trazer para a formação docente. Radicalmente, $\mathrm{Br}$ zezinski (2002 apud LIMA, 2012) considera as universidades lócus adequado à formação de professores, dada sua tradição e articulação entre ensino e pesquisa. Compreendemos que são preocupações legítimas e merecem atenção. Nenhuma delas, no entanto, deve servir para diminuir o trabalho dos IFs na formação de professores, subestimando seu potencial.

É questionável a crítica do exclusivismo das universidades em formação de docentes para a Educação Básica, pois os IFs assemelham-se a essas instituições para fins de regulação, avaliação e supervisão das instituições e dos cursos de Educação Superior (BRASIL, 2008, artigo 2ํ). Partilham ainda com elas o fato de serem autarquias, possuírem autonomia administrativa, patrimonial, financeira, didático-pedagógica e disciplinar.

Um diferencial importante entre os IFs e as universidades é que na Lei de criação dos institutos "a prioridade fundamental deles ancora-se no oferecimento da educação técnica e tecnológica, ao estímulo à produção de conhecimento pertinente às tecnologias da produção, ao fortalecimento dos arranjos produtivos socioculturais" (PANIAGO, 2016, p. 94).

Em razão disso, existe a predominância de cursos técnicos, correspondendo a quase $82,5 \%$ dos cursos, contra $17,5 \%$ de cursos de formação de professores (BRASIL, 2019b). Silva e Melo (2018) buscaram os motivos do não atendimento à Lei dos IFs que preconiza $50 \%$ de cursos técnicos nível médio e $20 \%$ de formação de professores. Eles afirmam que a Licenciatura é, historicamente, marcada pela desvalorização da docência, pelo baixo status social e pelo alto número de evasão:

[...] acrescido à dificuldade de docentes bacharéis em formar licenciados, o que propicia resistências, tanto internas (docentes e gestores, por exemplo), quanto externas à instituição, já que a sociedade tende a solicitar e procurar cursos que julgam ter melhor status social (SILVA; MELO, 2018, p. 11).

Outra razão para o não atendimento a essa função pode estar na própria interpretação da Lei no 11.892, que expressa uma estreita relação dos IFs com o setor produtivo e a pesquisa aplicada, estimulando o desenvolvimento de soluções técnicas e atendendo às vicissitudes do mundo do trabalho (OTRANTO, 2010). Na visão de Magalhães e Castioni (2019, p. 741), as pesquisas aplicadas no âmbito dos IFs remetem "a atuação dos docentes a fim de propor soluções para aprimorar as atividades econômicas locais 
nos arredores desses campi". Desse modo, parece-nos que se instalam ambiguidades no que se refere à formação de professores, dando a impressão de que os institutos, ao possuírem maior afinidade com a EPT, poderiam remeter a uma formação de professores, excessivamente, "relacionada com o desenvolvimento da técnica e da tecnologia" (LIMA, 2012, p. 94), "com currículos mais flexíveis, em sintonia com o mundo produtivo" (p. 111).

Na visão de Paniago (2016), os IFs estariam dissociando a pesquisa das atividades de ensino, ao terem uma visão um tanto limitada da atividade de pesquisa, tomando-a como pesquisa aplicada, além de esta ser "dirigida aos setores empresariais e industriais", conforme afirma Otranto (2010, p. 102). Assim, para essa autora, os IFs constituíram-se como modelos alternativos às "universidades de pesquisa", consideradas pelo Banco Mundial "instituições dispendiosas e inadequadas às necessidades e recursos dos países mais pobres".

Uma sinalização importante de que a pesquisa tem sido efetivada nos IFs é o quantitativo de cursos de Pós-Graduação lato e stricto sensu, que, juntos, somam 731 programas e 46.609 matrículas (BRASIL, 2019b). Resta-nos saber se entre o que está proposto regimentalmente para os IFs e o que efetivamente é feito na formação docente nestes espaços há a possibilidade para que a formação aconteça de modo diferente, sem desconsiderar a importância da pesquisa para a formação do professor, o que inclui a oferta de Pós-Graduação na área de Ensino e Educação.

Não consideramos que a falta de tradição em formação de professores seja um problema que desmereça o trabalho dos IFs. É fato que essas instituições, historicamente, não foram projetadas para formar docentes para a Educação Básica, mas foram, sim, usadas para tanto. Isso aconteceu por conta de um contexto político, de um cenário educacional e de uma história da profissão docente, que possui particularidades no contexto brasileiro. A utilização dos IFs para a formação docente foi abordada por Lima (2012), que revelou que toda a preexistência de infraestrutura e recursos humanos (docentes, técnicos administrativos) destinados à EPT parece ser vantajosa, também, à formação docente. Talvez aqui resida mais uma pista sobre a contribuição que os IFs podem dar à formação de professores: facilitar a integração entre os diferentes níveis de ensino, produzindo e compartilhando saberes forjados neste processo; questões ainda em aberto; só o tempo, o empenho e o trabalho comprometidos dirão se os IFs têm uma forma própria de pensar e fazer a formação docente.

É preciso que levemos em conta o contexto atual dos IFs, entrelaçando sua história e as múltiplas formas que os cursos de formação docente assumem nessas instituições. Em termos de políticas educacionais, os IFs representam uma conquista para o país por tudo o que a rede de EPT viveu e sofreu até aqui. Ao ganhar um novo status, o desafio amplia-se e deve ser enfrentado na prática, no dia a dia das experiências dos IFs e nos cenários abertos por eles.

A discussão de Ciavatta (2010) preocupa-se também com o destino do Ensino Médio nas instituições federais, ao adquirir novas feições ao longo de sua história. Desde os Cefets e, mais recentemente, passando pelos IFs, houve a vinculação dessas instituições com o Ensino Superior, o que deu a elas, segundo Ciavatta (2010), o status de universidade. Em razão disso, Magalhães e Castioni (2019), citando o trabalho de Moraes 
(2016), colocam que se gerou uma tensão da Identidade de Escola Técnica versus Vontade de Universidade, transformando os IFs em mais um espaço de produção de ativos intelectuais, como ocorre nas universidades.

Parece-nos que, neste processo, embora os institutos tenham a prerrogativa legal para verticalizar o ensino, indo da Educação Básica até a Pós-Graduação, a prioridade tenderá a ser conferida à oferta da Educação Superior em detrimento do nível médio, o que é assinalado por Flach (2014) e Ciavatta (2010). Essas autoras explicam que o Ensino Médio acaba ficando sob responsabilidade, principalmente, dos professores substitutos, enquanto os professores doutores, mais qualificados, dedicam-se ao Ensino Superior, à pesquisa e à Pós-Graduação.

Compartilhamos, com Ciavatta (2010), a crença de que em um país marcado por desigualdades, como o Brasil, defender o Ensino Médio público, especialmente nas escolas da rede federal, "é uma exigência de ordem ética e política", considerando que "são os melhores cursos de educação pública do País" (p. 167). No Exame Nacional do Ensino Médio (Enem), um dos parâmetros para atestar a qualidade da educação de nível médio oferecida pela RFEPCT, Dutra et al. (2019) destacaram que a média geral dos estudantes, no ano de 2015 , data da última divulgação da rede federal, foi de 572,42 pontos, superando as redes estadual $(492,39)$, municipal $(520,40)$ e privada $(570,41)$.

Os IFs inserem-se em um contexto mais amplo das políticas educacionais, as quais "desde os anos 1990 vieram se aproximando de objetivos econômicos e político-ideológicos do capitalismo monopolista para ajustar os países periféricos ao capitalismo dos países centrais" (CIAVATTA, 2010, p. 162). Tais políticas educacionais estão alinhadas ao neoliberalismo e à formação voltada ao interesse do capital, vinculadas às determinações de organismos internacionais, como Banco Mundial, Organização para a Cooperação e o Desenvolvimento Econômico (OCDE) e o Fundo Monetário Internacional (FMI) (MAUÉS, SEGENREICH, OTRANTO, 2015; CIAVATTA 2010; OTRANTO, 2010).

Paniago (2016) pontua que não se pode negar que a educação profissional no Brasil sempre se subordinou aos interesses do mercado capitalista. Com isso, busca-se a formação técnica de mão de obra barata para o mercado de trabalho e não a preparação para o mundo do trabalho, como muitas vezes ocorre no Sistema S. Como fazer a diferença ante a isso? Como os IFs podem resistir à sedução de se alinhar à lógica capitalista, sabendo que a lógica do capital não permite uma educação emancipadora, promotora da igualdade e da justiça social.

Parece-nos prudente pensar sobre a identidade dos IFs, que, de antemão, não nos remete a algo estático. Essas instituições metamorfosearam-se. De uma longa experiência voltada exclusivamente à EPT, ligada à formação para o trabalho (PANIAGO, 2016; LIMA, 2012), passaram a ser instituições que atendem a demandas formativas da Educação Básica e profissional, inclusive a formação de professores até a Pós-Graduação. Conforme Paniago (2016) nos lembra, porém, não é por força da lei que essa atuação ampla se efetivará, mas é por meio de um longo processo de discussão, reflexão e empenho que se poderá compreender tais metamorfoses nos IFs. 


\section{CONSIDERAÇÕES FINAIS}

Temos em mente que o fenômeno da formação de professores nos IFs é permeado por contradições, como assinala Lima (2012). De um lado, salta aos olhos a expansão dessas instituições, levando uma formação pública e gratuita a diversas regiões do Brasil. Do outro, vemos com preocupação as concepções políticas da Lei dos IFs, por estarem voltadas ao interesse do capital, promovendo a formação que separa trabalho manual e trabalho intelectual. Para Magalhães e Castioni (2019, p. 748), a dualidade entre trabalho manual (voltado à formação técnica) e o trabalho intelectual (voltado à formação em curso superior) reforça a visão "de que somente os nascidos num determinado estrato social é que terão sucesso em suas trajetórias", daí a excessiva valorização de estudos em nível superior.

Compreendemos que a possibilidade de verticalização do ensino, indo da Educação Básica e profissional até a Educação Superior em um mesmo local, é uma contribuição importante que os IFs inseriram na formação de professores. Isso promove a integração não somente em termos de aproveitamento do quadro docente, o qual pode atuar em diferentes níveis e modalidades simultaneamente, mas entre os estudantes dos diferentes níveis e sua convivência em diversos espaços, como laboratórios, eventos acadêmicos, projetos de pesquisa e ensino.

Dialogando com os referenciais que têm se debruçado sobre a formação de professores nos IFs, consideramos a pertinência de pensar este tipo de formação de modo crítico, levando-se em conta as marcas históricas dessas instituições. Uma dessas marcas é a qualidade da Educação Básica de nível médio, garantindo a seus estudantes os melhores desempenhos no Enem. A formação docente, nesse cenário, pode se enriquecer pelo íntimo contato com a Educação Básica, privilegiando não somente as áreas das ciências e matemática, mas também as disciplinas da EPT, que tanto sofrem por falta de professores especializados.

Torna-se ainda mais relevante o debate a respeito da formação de professores no IFs diante da conjuntura histórico-política atual, marcada por uma política neoliberal que ameaça as conquistas advindas da criação da RFEPCT. Quem sabe estejamos diante de uma nova arena de disputa, não apenas no âmbito das políticas públicas educacionais, mas na própria comunidade acadêmica. Debatemos a formação de professores nos IFs como um novo objeto de investigação da área da Educação, apontando as contribuições desses locais e acreditando que são loci de uma formação específica marcada pela verticalização do ensino e pela interiorização.

Para além de uma visão entusiasmada diante da Lei dos IFs e da concretude de sua atuação, se tomarmos a realidade histórica à qual o Brasil atravessa desde o ano de 2016 com o impeachment da ex-presidente Dilma Rousseff, culminando com as eleições de 2018, o cenário é desanimador. Temos assistido a quase total paralisia das políticas educacionais; um verdadeiro ataque à Educação e seus profissionais. A formação inicial e continuada de professores nos IFs e nas universidades atravessam momentos difíceis, principalmente em disciplinas específicas, como ciências e matemática, que, como sabemos, têm déficit enorme de professores nas redes de ensino da Educação Básica. 


\section{REFERÊNCIAS}

BRASIL. Instituto Nacional de Estudos e Pesquisas Educacionais Anísio Teixeira (Inep). Censo da Educação Superior 2018: notas estatísticas. Brasília, 2019a. Disponível em: http://download.inep.gov.br/educacao_ superior/censo_superior/documentos/2019/censo_da_educacao_superior_2018-notas_estatisticas.pdf. Acesso em: 30 maio 2020.

BRASIL. Câmara dos Deputados. Revisão orçamentária 2019 diagnóstico para educação: possibilidades e perspectivas. Brasília, 2018a. Disponível em: https://www2.camara.leg.br/orcamento-da uniao/estudos/2018/Revisooramentria2019_Educao_diagnstico.pdf. Acesso em: 2 jun. 2020.

BRASIL. Ministério da Educação. Plataforma Nilo Peçanha, 2019b. Disponível em: http://resultados.plataformanilopecanha.org/. Acesso em: 2 maio 2020.

BRASIL. Ministério da Educação, 2018b. Disponível em: http://redefederal.mec.gov.br/expansao-da-rede-federal. Acesso em: 29 ago. 2018.

BRASIL. Congresso Nacional e Senado Federal. Emenda Constitucional no 95. Altera o Ato das Disposições Constitucionais Transitórias, para instituir o Novo Regime Fiscal, e dá outras providências. Diário Oficial [da] República Federativa do Brasil, Poder Executivo. Brasília, DF, 16 dez. 2016, Seção 1, p. 2. Disponível em: http://www.planalto.gov.br/ccivil_03/constituicao/emendas/emc/emc95.htm. Acesso em: 21 ago. 2020.

BRASIL. Uma nova proposta de educação profissional tecnológica: concepções e diretrizes dos institutos federais. Brasília, DF: MEC; Setec, 2010.

BRASIL. Congresso Nacional. Lei no 11.892, de 29 de dezembro de 2008. Institui a Rede Federal de Educação Profissional Científica e Tecnológica e dá outras providências. Diário Oficial [da] República Federativa do Brasil, Poder Executivo, Brasília, DF, 30 dez. 2008, Seção 1, p. 1. Disponível em: http://www.planalto. gov.br/ccivil_03/_ato2007-2010/2008/lei/l11892.htm. Acesso em: 2 jun. 2020.

BRASIL. Conselho Nacional de Educação. Diretrizes Curriculares Nacionais para Cursos de Formação de Professores para a Educação Básica, 2006. Disponível em: http://portal.mec.gov.br/cne/arquivos/pdf/ pcp005_06.pdf. Acesso em: 2 jun. 2020.

BRASIL. Conselho Nacional de Educação. Diretrizes Curriculares Nacionais para a Formação de Professores da Educação Básica, em nível superior, curso de Licenciatura, de Graduação plena, 2001. Disponível em: http://portal.mec.gov.br/cne/arquivos/pdf/009.pdf. Acesso em: 2 jun. 2020.

BRASIL. Decreto no 3.462, de 17 de maio de 2000. Dá nova redação ao art. 8o do Decreto no 2.406, de 27 de novembro de 1997, que regulamenta a Lei no 8.948, de 8 de dezembro de 1994, Brasília, 2000. Disponível em: http://www2.camara.leg.br/legin/fed/decret/2000/decreto-3462-17-maio-2000-377149-normape.html. Acesso em: 28 ago. 2018.

BRASIL. Decreto no 2.406, de 27 de novembro de 1997. Regulamenta a Lei no 8.948, de 8 de dezembro de 1994, e dá outras providências. Disponível em: http://portal.mec.gov.br/setec/arquivos/pdf/dec2406. pdf. Acesso em: 28 ago. 2018.

BRASIL. Lei no 9.394/1996 - Lei de Diretrizes e Bases da Educação Nacional. Disponível em: https:// www2.senado.leg.br/bdsf/bitstream/handle/id/529732/lei_de_diretrizes_e_bases_1ed.pdf. Acesso em: 2 jun. 2020.

BRASIL. Decreto no 7.566, de 23 de setembro de 1909. Crêa nas capitaes dos Estados da Republica Escolas de Aprendizes Artifices, para o ensino profissional primario e gratuito. Disponível em: https://www2. camara.leg.br/legin/fed/decret/1900-1909/decreto-7566-23-setembro-1909-525411-publicacaooriginal-1-pe.html. Acesso em: 2 maio 2020.

BREZINSKI, M. A. S. et al. A evolução orçamentária da Rede Federal de Educação Profissional, Científica e Tecnológica. Boletim iDEIA, n. 1, 2015.

CALDAS, L. A formação de professores e a capacitação de trabalhadores da EPT. In: PACHECO, E. (org.). Institutos Federais: uma revolução na educação profissional e tecnológica. Brasília; São Paulo: Editora Moderna, 2011. p. 33-45.

CAMARGO, A. M. M.; CASTRO, A. M. D. A. Expansão da educação superior e formação de professores nos Estados do Pará e do Rio Grande do Norte. Educação em Revista, Belo Horizonte, v. 32, n. 4, p. 119-146, out./dez. 2016.

CAMPELLO, Ana Margarida. “Cefetização” das Escolas Técnicas Federais - projetos em disputa, nos anos de 1970 e nos anos de 1990. Educ. Tecnol., Belo Horizonte, v. 12, n. 1, p. 26-35, jan./abr., 2007. 
CASTIONI, R. O papel dos Institutos Federais na promoção do desenvolvimento local. In: SOUZA, E. C. L.; CASTIONI, R. (org.). Institutos Federais: os desafios da institucionalização. Brasília: Editora Universidade de Brasília, 2012. p. 45-56.

CIAVATTA, M. Universidades tecnológicas: horizonte dos Institutos Federais de Educação, Ciência e Tecnologia (IFETS)? In: MOLL, J. et al. Educação profissional e tecnológica no Brasil contemporâneo - desafios, tensões e possibilidades. Porto Alegre: Artmed, 2010. p. 159-174.

DUTRA, R. S. et al. O que mudou no desempenho educacional dos Institutos Federais do Brasil? Ensaio: Avaliação e Políticas Públicas em Educação, Rio de Janeiro, v. 27, n. 104, p. 631-653, jul./set. 2019.

FLACH, A. Formação de professores nos Institutos Federais: estudo sobre a implantação de um curso de Licenciatura em um contexto de transição institucional. 2014. 210 f. Tese (Doutorado em Educação) - Universidade do Vale do Rio dos Sinos - Unisinos, São Leopoldo, 2014.

FREITAS, H. C. L. A reforma do Ensino Superior no campo da formação dos profissionais da Educação Básica: as políticas educacionais e o movimento dos educadores. Educação \& Sociedade, a. XX, n. 68, p. 17-44, dez. 1999.

GATTI, B.; BARRETO, E. S. S. Professores do Brasil: impasses e desafios. Brasília: UNESCO, 2009.

GEBRIM, T. A educação profissional brasileira na letra da lei. 2017. 77 f. Monografia (Programa de Pós-Graduação Lato sensu em Políticas e Gestão da Educação Profissional e Tecnológica) - Instituto Federal de Educação, Ciência e Tecnologia de Goiás (IFG), Goiânia, 2017.

LIMA, F. B. G. A formação de professores nos Institutos Federais de Educação, Ciência e Tecnologia: um estudo da concepção política. 2012. 282 f. Dissertação (Mestrado em Educação) - Faculdade de Educação da Universidade de Brasília (UnB), Brasília, 2012.

MAGALHÃES, G. L.; CASTIONI, R. Educação profissional no Brasil - expansão para quem? Ensaio: Avaliação e Políticas Públicas em Educação, Rio de Janeiro, v. 27, n. 105, p. 732-754, out./dez. 2019.

MAUÉS, O. C.; SEGENREICH, S. C. D.; OTRANTO, C. R. As políticas de formação de professores: a expansão comprometida. Revista Educação em Questão, Natal, v. 51, n. 37, p. 42-72, jan./abr. 2015.

MOTA, R. D. P. Identidades em trânsito: a pesquisa nas licenciaturas em Química dos Institutos Federais de Goiás. 2015. 184 f. Tese (Doutorado em Química) - Universidade Federal de Goiás (UFG), Goiânia, 2015.

NEVES, C. E. B. Ensino Superior no Brasil: expansão, diversificação e inclusão. Grupo de Estudos sobre Universidade (GEU). Porto Alegre: UFRGS, 2012.

OTRANTO, C. R. Criação e implantação dos Institutos Federais de Educação, Ciência e Tecnologia - IFETS. Retta, v. 1, n. 1, p. 89-108, jan./jun. 2010.

PACHECO, E. Institutos Federais: um futuro em aberto. In: SOUZA, E. C. L.; CASTIONI, R. (org.). Institutos Federais: os desafios da institucionalização. Brasília: Editora Universidade de Brasília, 2012. p. 7-11.

PANIAGO, R. N. Contribuições do Programa Institucional de Bolsa de Iniciação para a Aprendizagem da Docência Profissional. 2016. 367 f. Tese (Doutorado em Ciências da Educação) - Universidade do Minho, Instituto de Educação, Minho, 2016.

SEGENREICH, A. C. D.; CASTANHEIRA, A. M. Expansão, privatização e diferenciação da Educação Superior no Brasil pós-LDBEN/96: evidências e tendências. Ensaio: Avaliação e Políticas Públicas em Educação, Rio de Janeiro, v. 17, n. 62, p. 55-86, jan./mar. 2009.

SILVA, L. B.; CASTRO, A. M. D. A. Política de formação de professores: variação do lócus de formação e a experiência do CEFET-RN. Educação em Questão, v. 30, p. 99-126, 2007.

SILVA, P. F.; MELO, S. D. G. O trabalho docente nos Institutos Federais no contexto de expansão da Educação Superior. Educação e Pesquisa, São Paulo, v. 44, e177066, 2018. 